\title{
Supplementary File
}

\section{In-Situ Studies of Methanol Decomposition Over $\mathrm{Cu}(111)$ and $\mathrm{Cu}_{2} \mathrm{O} / \mathrm{Cu}(111)$ : Effects of Reactant Pressure, Surface Morphology and Hot Spots of Active Sites}

\footnotetext{
Ivan Orozco ${ }^{1}$, Erwei Huang ${ }^{1}$, Mausumi Mahapatra ${ }^{2}$, Rui Shi ${ }^{1}$, Jindong Kang ${ }^{1}$, Slavomír Nemšák ${ }^{3}$, Sanjaya D. Senanayake ${ }^{2}$, Ping Liu ${ }^{1,2}$, José A. Rodríguez ${ }^{1,2 *}$

${ }^{1}$ Department of Chemistry, Stony Brook University, Stony Brook, NY 11794, USA

${ }^{2}$ Chemistry Division, Brookhaven National Laboratory, Upton, NY 11973, USA

${ }^{3}$ Advanced Light Source, Lawrence Berkeley National Laboratory, Berkeley, CA 94720, USA

*Corresponding Author: rodrigez@bnl.gov
} 

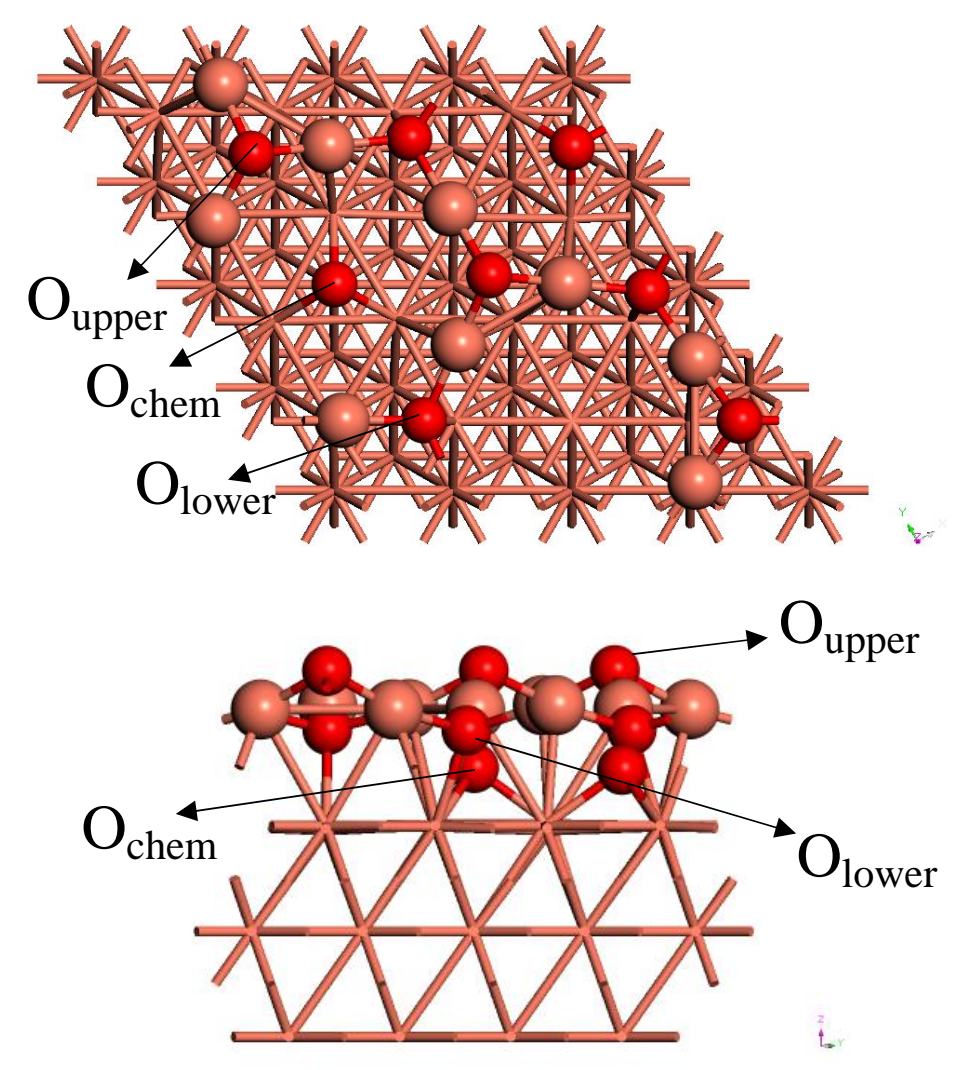

Figure S1: Structure illustration of top and side views for the $\mathrm{Cu}_{2} \mathrm{O} / \mathrm{Cu}(111)$ model. Brown: $\mathrm{Cu}, \mathrm{Red}: \mathrm{O}$. 


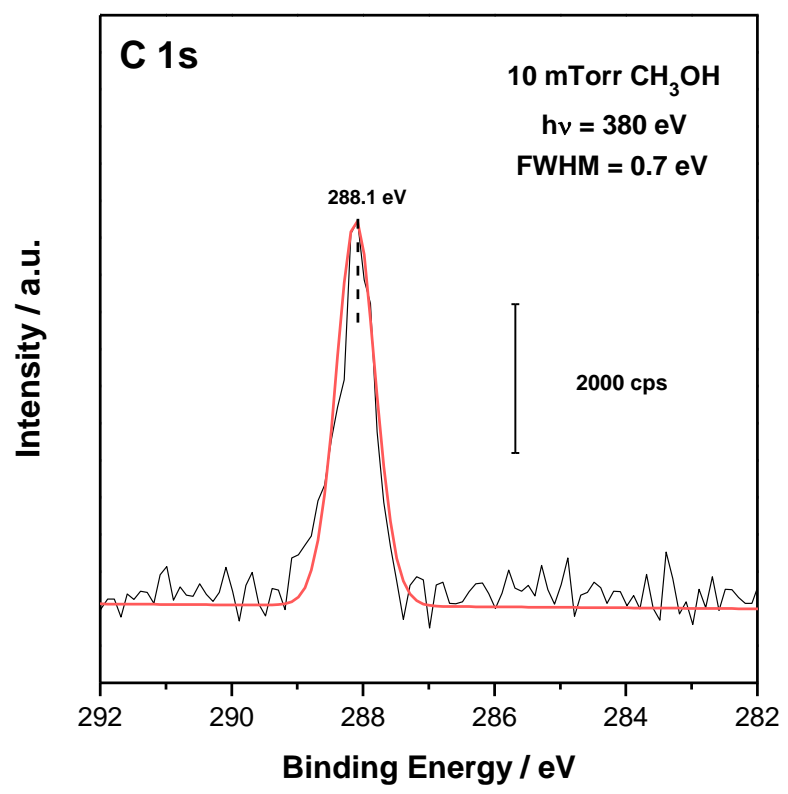

Figure S2: 10 mTorr $\mathrm{CH} 3 \mathrm{OH}$ with $\mathrm{Cu}(111)$ retracted. The intensity of this narrow peak (0.7 eV FWHM) was $\sim 5,000 \mathrm{cps}$ (count per second) above the background in the $\mathrm{C} 1 \mathrm{~s}$ region with the sample retracted, allowing for a large-area detection of gas phase methanol. For comparison, the as-prepared spectrum for the $\mathrm{Cu}(111)$ in position has a nominal value of $\sim 35,000 \mathrm{cps}$ for the inelastically scattered electrons constituting the background of a $\mathrm{C} 1 \mathrm{~s}$ scan at this photon energy; the relatively low signal for the large-area methanol gas phase peak combined with the decrease in area occupied by gas with the sample in position lead overall to a negligible methanol gas peak in the spectra presented herein. The lack of an observable methanol gas phase peak simplifies the identification of surface species. Additionally, the peak width gives us an estimation of the upper end of the speciation resolution obtained at this photon energy $(\mathrm{h} v=380 \mathrm{eV})$ in terms of peak broadening. 

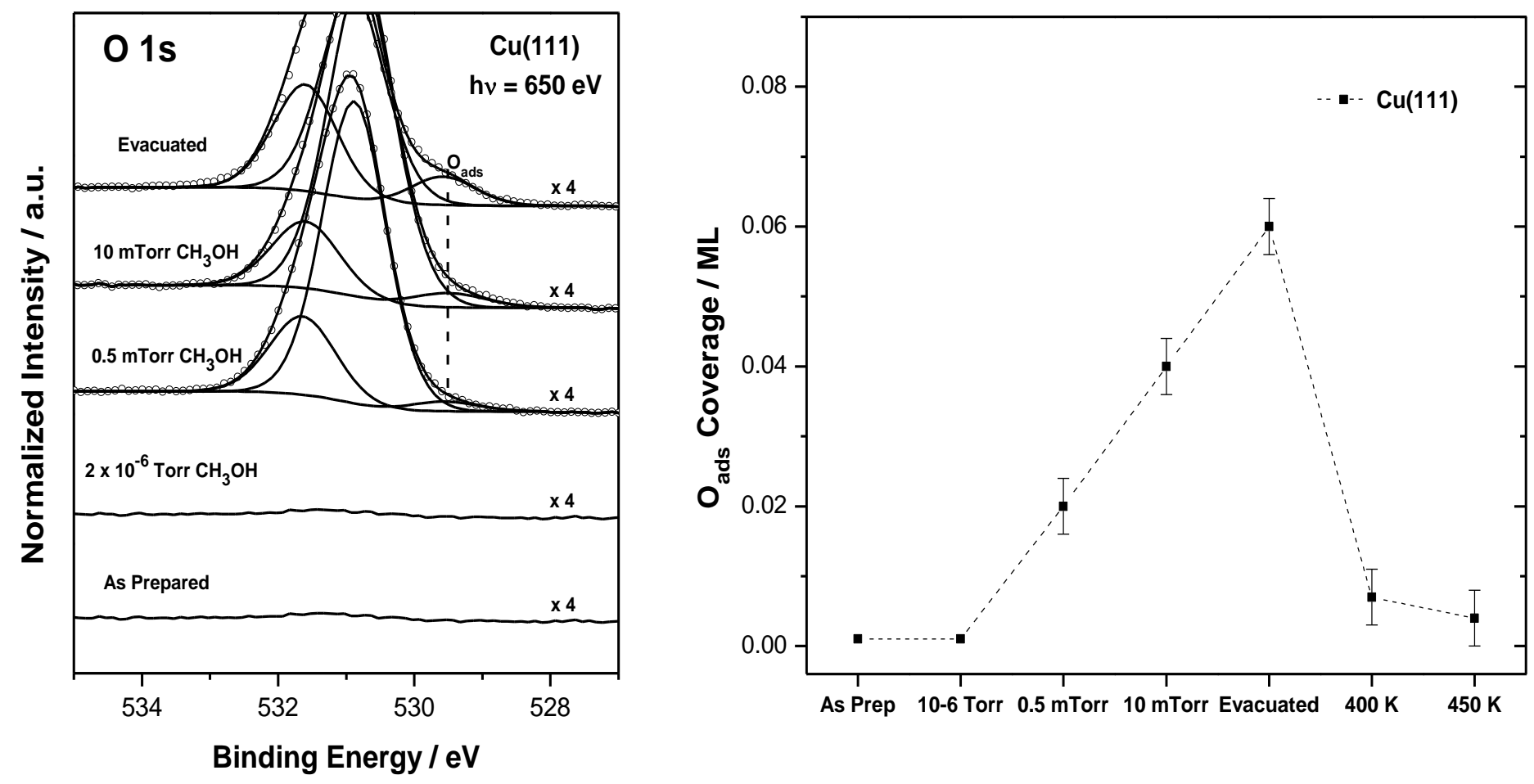

Figure S3: Small scale view of the $\mathrm{O} 1 \mathrm{~s}$ for $\mathrm{Cu}(111)$ exposed to methanol (left) and quantification for corresponding $\mathrm{O}_{\text {ads }}$ (right). 

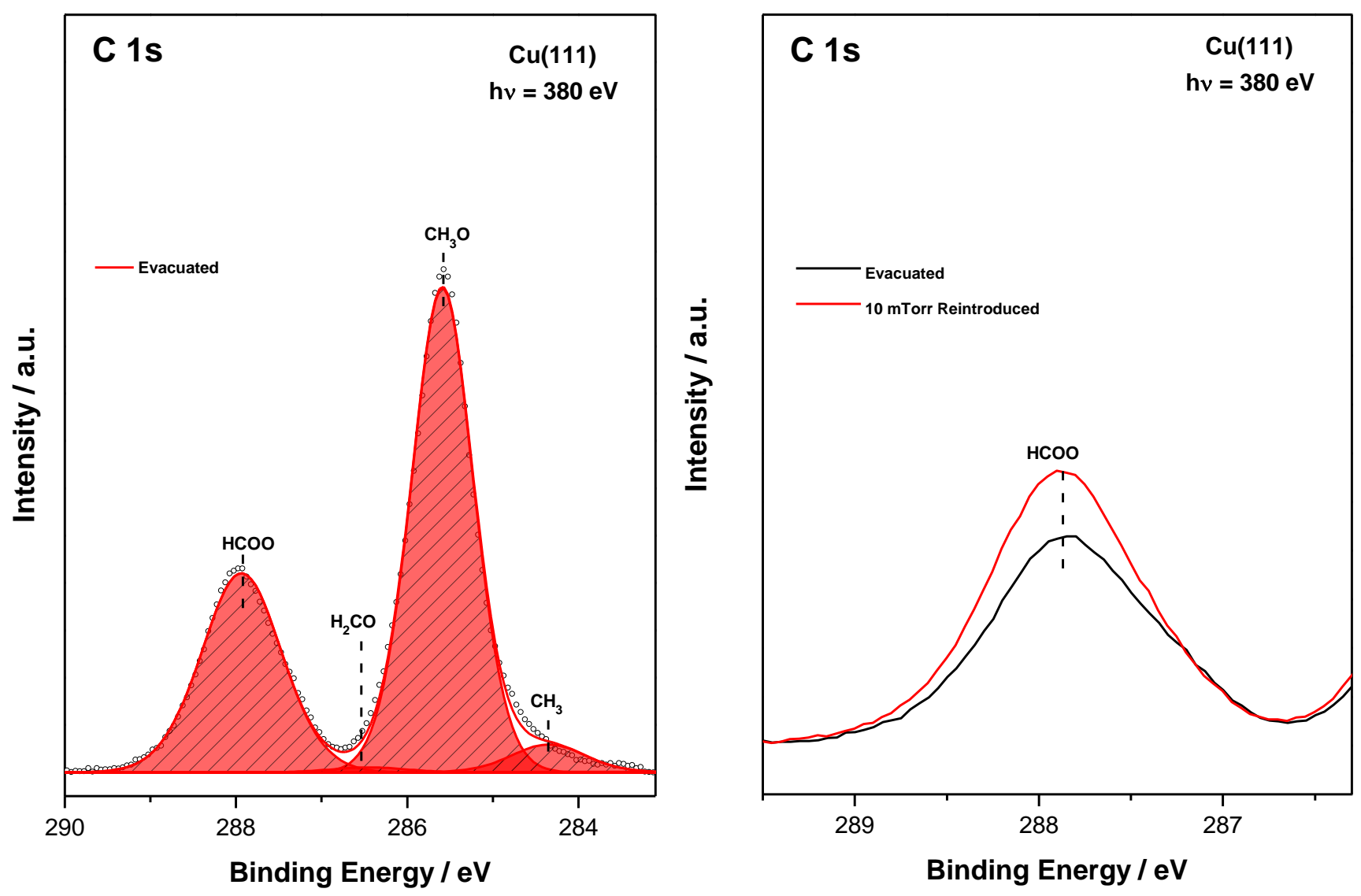

Figure S4: Left-side: Fitting for $\mathrm{Cu}(111)$ after methanol evacuation . Right-side: Comparison of formate (HCOO) signals for $\mathrm{Cu}(111)$ upon evacuation (black) and reintroduction of 10 mTorr methanol (red). A full set of spectra is shown in Figure 1 


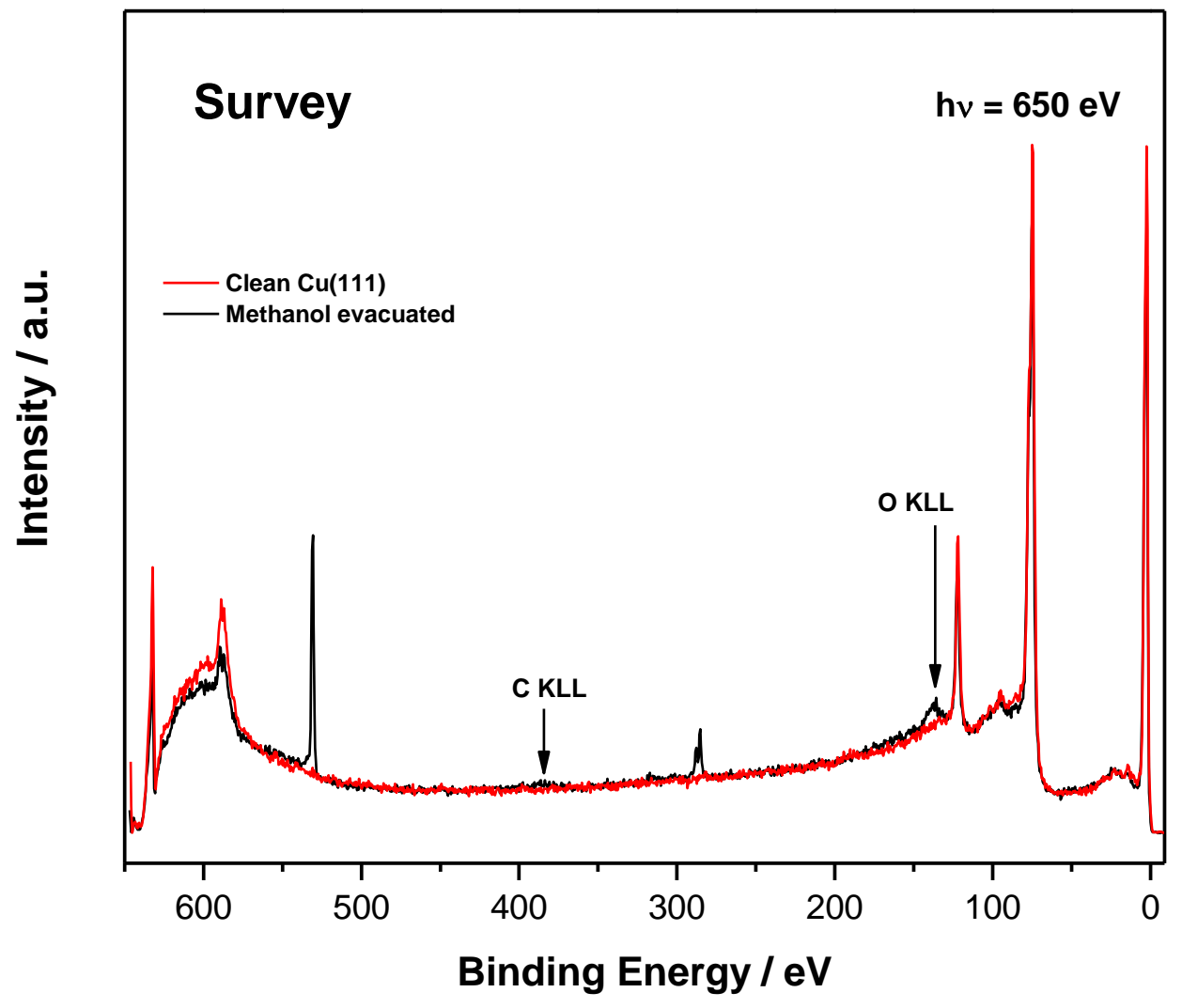

Figure S5: Wide energy range survey of clean $\mathrm{Cu}(111)$ (red) and $\mathrm{Cu}(111)$ after evacuation of 10 mTorr methanol (black). O KLL and C KLL Auger electrons are illustrated by arrows. 


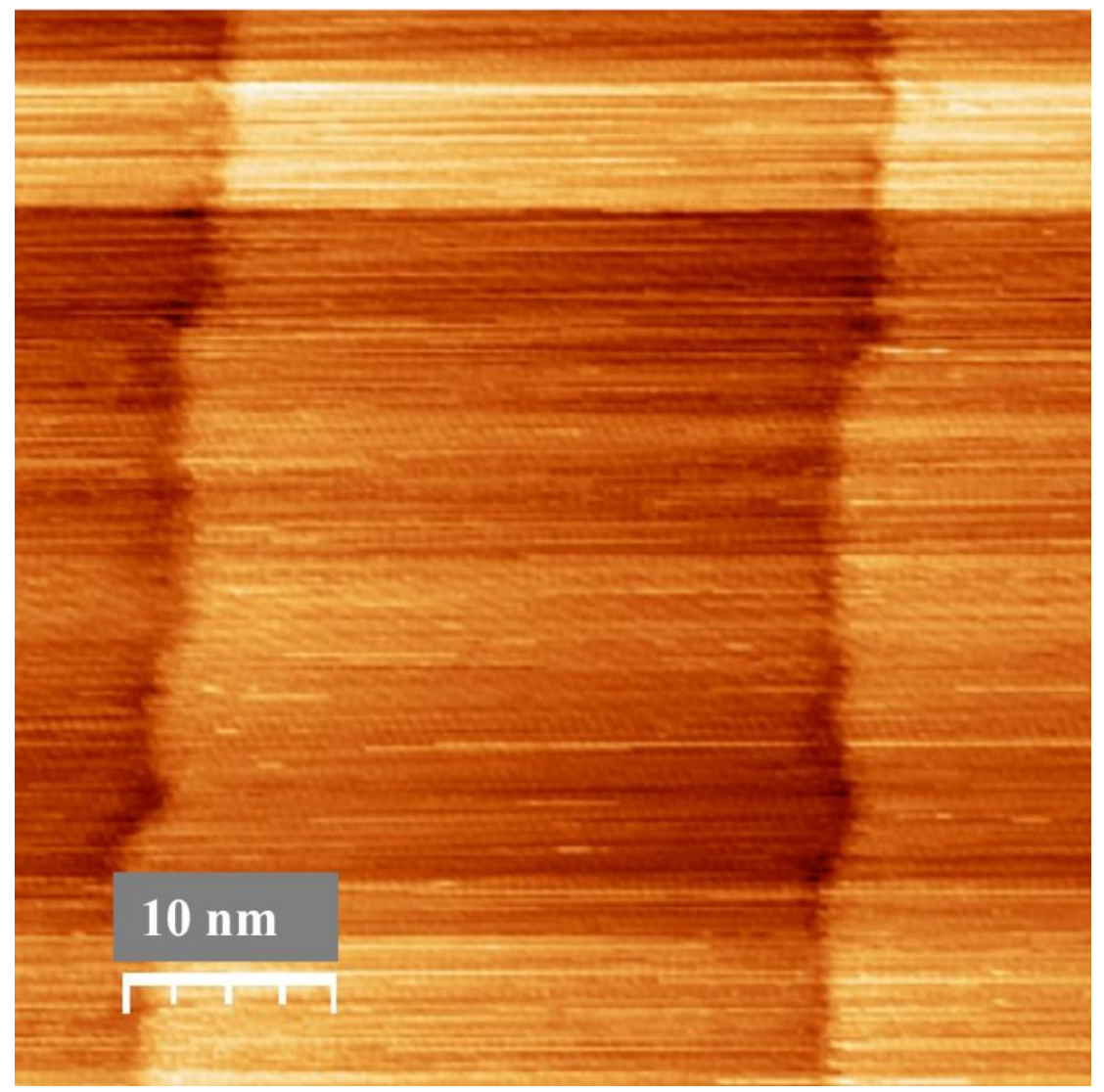

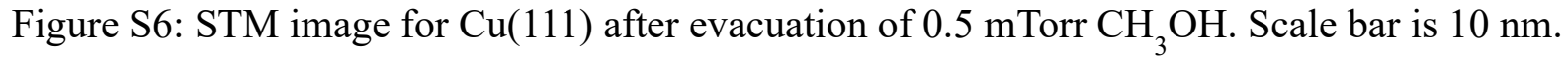




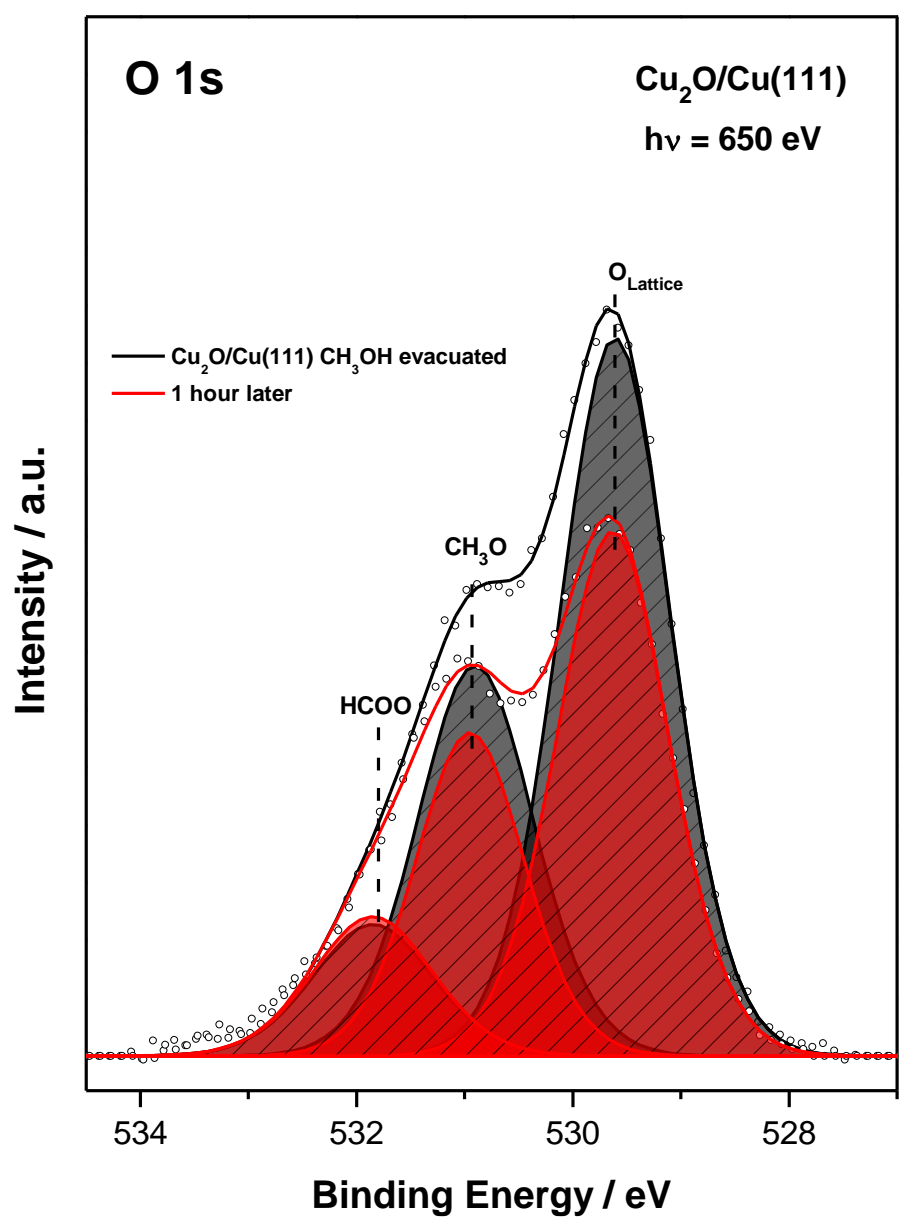

Figure S7: Overlay for $\mathrm{Cu}_{2} \mathrm{O} / \mathrm{Cu}(111)$ after evacuation of $\mathrm{CH}_{3} \mathrm{OH}$ (black) and after 1 hour under static vacuum and dark conditions (red). 


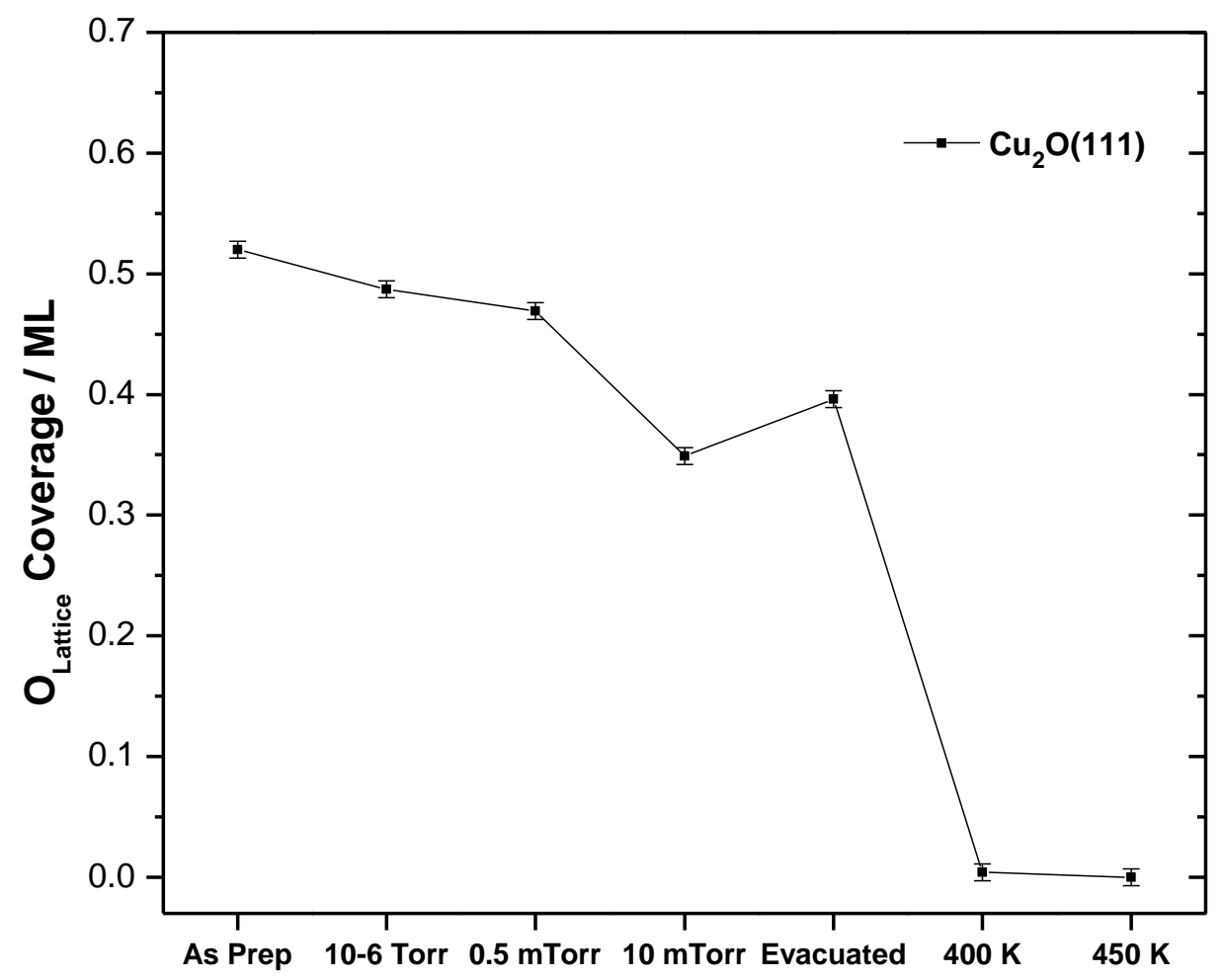

Figure S8: Quantification of lattice $\mathrm{O}$ for $\mathrm{Cu}_{2} \mathrm{O} / \mathrm{Cu}(111)$ exposed to methanol as a function of pressure and temperature. 
As prepared methanol/ $\mathrm{Cu}_{2} \mathrm{O} / \mathrm{Cu}(111) \quad$ Annealed to $400 \mathrm{~K}$

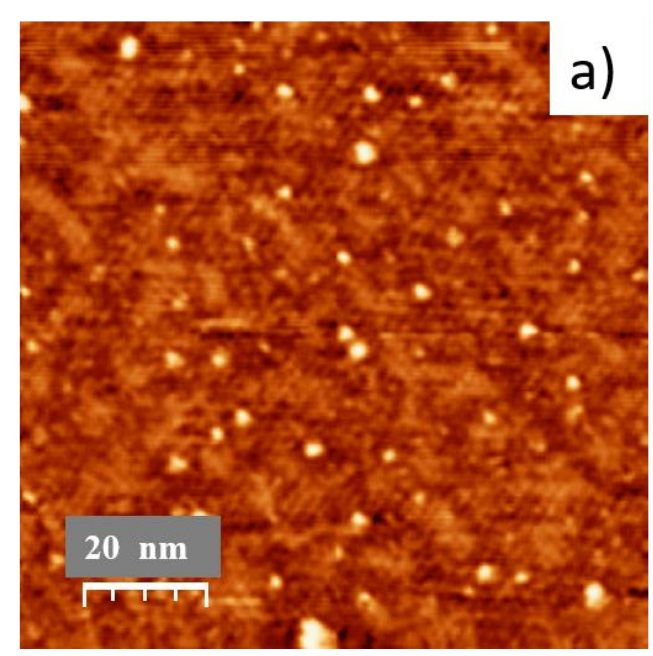

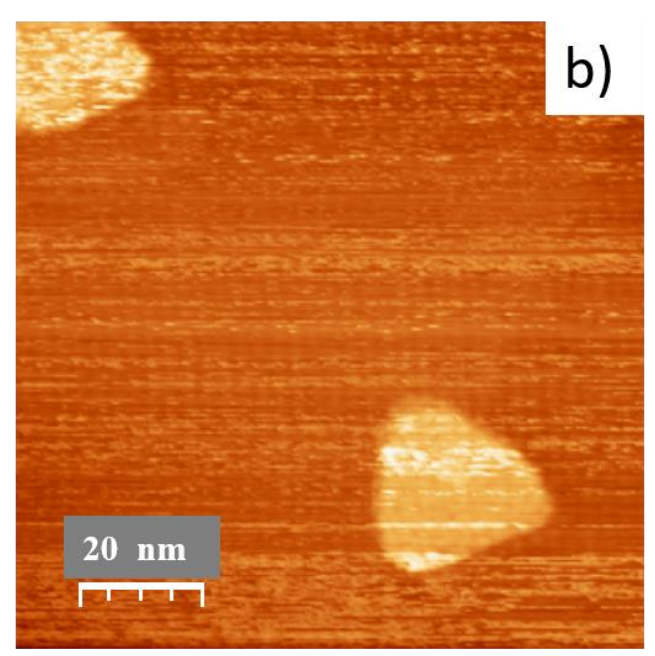

Annealed to $450 \mathrm{~K}$

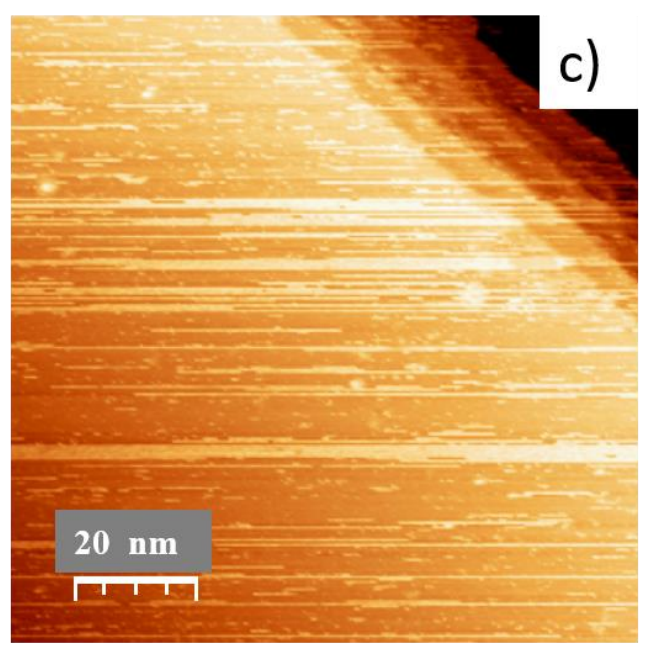

Figure S9: Large scale STM images for $\mathrm{Cu}_{2} \mathrm{O} / \mathrm{Cu}(111)$ terraces after exposure to $0.5 \mathrm{mTorr}$ methanol (a), annealed to $400 \mathrm{~K}$ (b), and annealed to $450 \mathrm{~K}$ (c). 

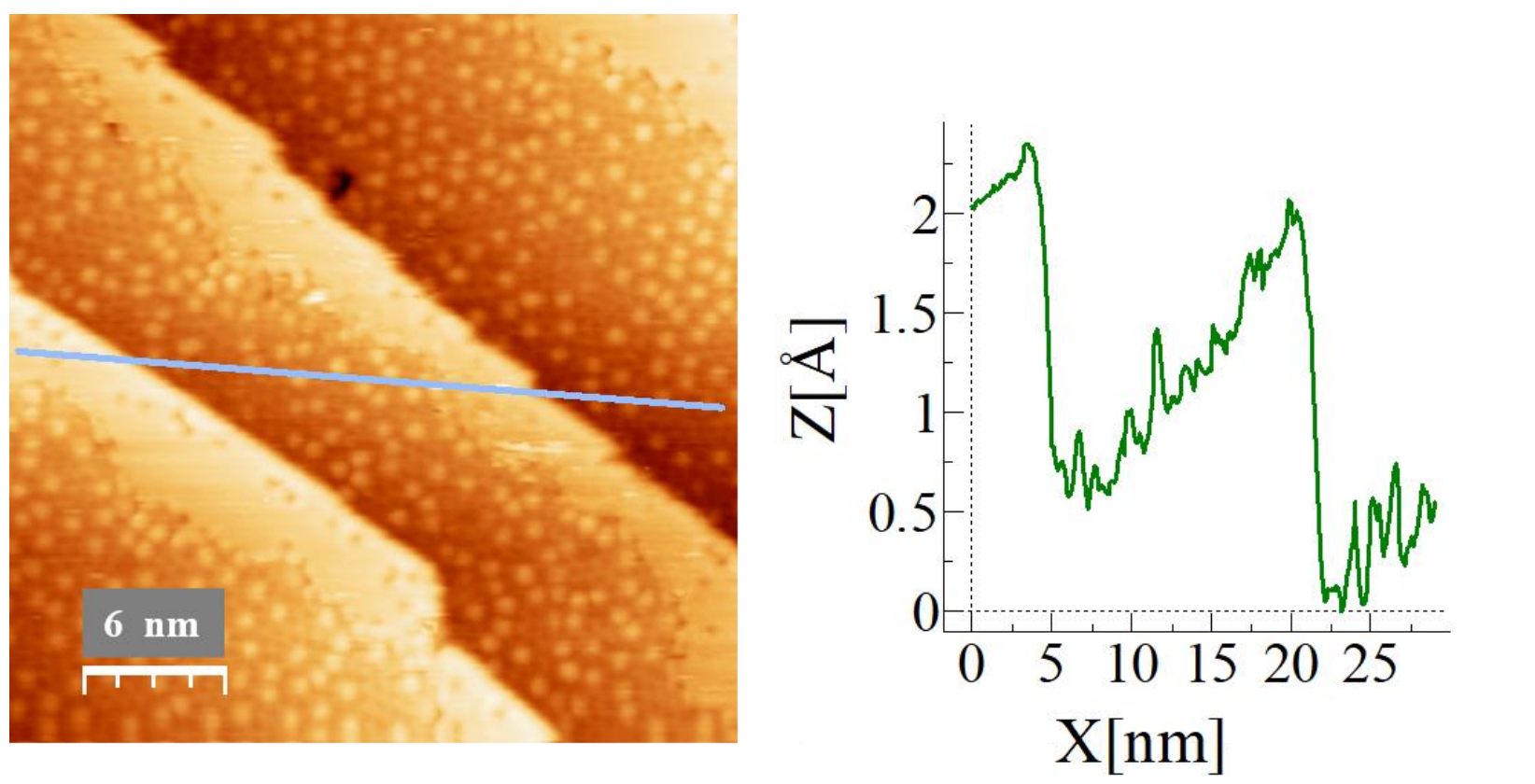

Figure S10: Line profile measurement for Figure 7e, $\mathrm{Cu}_{2} \mathrm{O} / \mathrm{Cu}(111)$ exposed to 0.5 mTorr methanol and evacuated, followed by annealing to $450 \mathrm{~K}$. STM image taken at $300 \mathrm{~K}$. The apparent $\mathrm{Cu}$ step height is $\sim 0.2 \mathrm{~nm}$. 


\section{$\mathrm{Cu}(111)$}

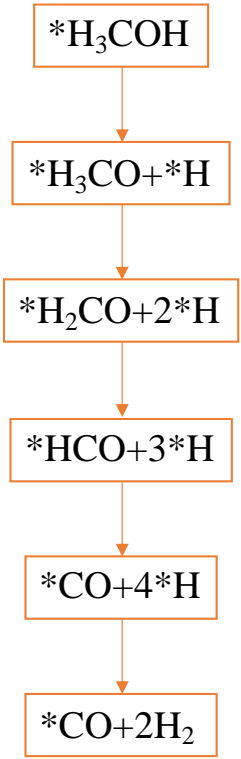

$\mathrm{Cu} \mathbf{u}_{2} \mathrm{O} / \mathrm{Cu}(111)$

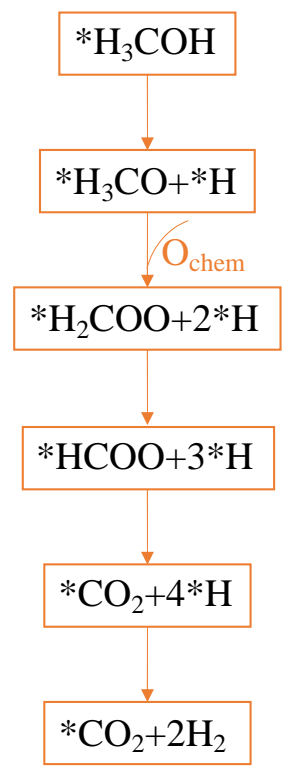

Figure S11: Schematic illustration for preferable $\mathrm{CH}_{3} \mathrm{OH}$ dissociation pathway on $\mathrm{Cu}(111)$ according to previous reports ${ }^{1,2}$ and $\mathrm{Cu}_{2} \mathrm{O} / \mathrm{Cu}(111)$ model in this study.

\section{References:}

1 Greeley, J.; Mavrikakis, M. Methanol Decomposition on Cu(111): A DFT Study. J. Catal. 2002, 208 (2), 291-300. https://doi.org/10.1006/jcat.2002.3586.

2 García-Muelas, R.; Li, Q.; López, N. Density Functional Theory Comparison of Methanol Decomposition and Reverse Reactions on Metal Surfaces. ACS Catal. 2015, 5 (2), 1027-1036. https://doi.org/10.1021/cs501698w. 